\title{
Qatar Healthcare Workers' COVID-19 Vaccine Hesitancy and Attitudes: A National Cross-Sectional Survey
}

\author{
Rajeev Kumar ${ }^{1,2 *}$, Majid Alabdulla ${ }^{1,2+}$, Nahid M. Elhassan ${ }^{1}$ and Shuja Mohd Reagu ${ }^{1,3}$ \\ ${ }^{1}$ Department of Psychiatry, Hamad Medical Corporation, Doha, Qatar, ${ }^{2}$ College of Medicine, Qatar University, Doha, Qatar, \\ ${ }^{3}$ Weill Cornell Medicine- Qatar, Doha, Qatar
}

OPEN ACCESS

Edited by:

Yann Joly,

McGill University, Canada

Reviewed by:

Prasanth Manohar,

Zhejiang University-University of Edinburgh Institute, China

Ma'n H. Zawati

McGill University, Canada

*Correspondence:

Rajeev Kumar

rkumar5@hamad.qa

†These authors share first authorship

Specialty section: This article was submitted to Infectious Diseases - Surveillance,

Prevention and Treatment, a section of the journal

Frontiers in Public Health

Received: 19 June 2021

Accepted: 30 July 2021

Published: 25 August 2021

Citation:

Kumar R, Alabdulla M, Elhassan NM and Reagu SM (2021) Qatar Healthcare Workers' COVID-19 Vaccine Hesitancy and Attitudes: A National Cross-Sectional Survey.

Front. Public Health 9:727748. doi: 10.3389/fpubh.2021.727748
Introduction: Healthcare workers are the critical frontline workforce of the COVD-19 pandemic and are considered a target group for vaccination. Hesitancy to vaccinate is a major concern that can jeopardize the vaccination programme. The hesitancy rates in the general population and healthcare workers (HCWs) vary globally, and more importantly, hesitancy in HCWs is of particular concern, as it can influence the wider population.

Materials and Methods: The present study evaluated the vaccine hesitancy rate and its sociodemographic and attitudinal factors among the HCWs in the state of Qatar. We conducted a national cross-sectional survey using a validated hesitancy measurement tool between October 15 and November 15, 2020. A total of 7,821 adults above the age of 18 years out of the 2.3 million adult Qatari residents completed the survey. While majority of the participants were from the general public, 1,546 participants were HCWs. Sociodemographic data, along with attitudes and beliefs around COVID-19 vaccination, were collected from the respondents.

Results: We found that $12.9 \%$ of the study participants showed vaccine hesitancy, defined as definitely or probably will not take the vaccine if offered, and $25.31 \%$ reported that they were unsure about the uptake of the COVID-19 vaccine. Female respondents were more hesitant toward the vaccine. Safety and efficacy concerns of vaccine were the significant predictors of vaccine hesitancy. The primary predictor for vaccine acceptance was a better understanding of the disease and vaccine.

Discussion: Overall, 1 in 8 HCWs were reluctant to get vaccinated against COVID-19, mainly due to concerns about the vaccine's efficacy and safety. Education about the vaccine's safety and efficacy can potentially improve acceptance among healthcare workers.

Keywords: COVID-19 vaccine, hesitancy, healthcare workers, safety, efficacy, VAX scale

\section{HIGHLIGHTS}

- This was the first study to report vaccine hesitancy in healthcare workers in Qatar, a country with the majority of the population being migrants.

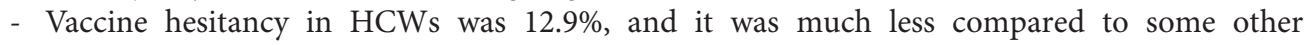
studies globally.

- The main predictors for vaccine hesitancy were female gender and concerns about the vaccine's safety and efficacy. 


\section{INTRODUCTION}

Coronavirus disease 2019 (COVID-19) is a highly contagious infectious disease caused by the Severe Acute Respiratory Syndrome Coronavirus 2 (SARS-CoV-2) that has transformed the world into a state never witnessed in our lifetime. In the absence of any valid treatment, globally, many countries have imposed strict preventive control measures to restrict the COVID-19 outbreak by implementing social distancing and compulsory use of face mask (1). Further, the development and distribution of vaccines have been one of the cardinal preventive strategies to lessen the spread of COVID-19 (2).

After one of the fastest vaccine development processes by countries and pharmaceutical companies worldwide, currently, the vaccines are available globally, including in Qatar. The Qatar Ministry of Public Health approved Pfizer BioNTech and Moderna COVID-19 vaccines, and the early recipients of vaccines were healthcare professionals, elderly patients and individuals affected with chronic and autoimmune disorders. However, the successful outcome of any vaccination strategy mainly relies on a high vaccine acceptance rate (3). Therefore, vaccine hesitancy is challenging for healthcare professionals and the Ministry of health to build confidence in an emergencyreleased vaccine rollout to the public.

Vaccine hesitancy is defined as "the delay in acceptance or refusal of vaccination despite the availability of vaccination services." Further, it is not an all or none phenomenon, which means, some will definitely not take a Covid-19 vaccine if offered, whereas others are unsure of their intention to get vaccinated. Vaccine hesitancy is a global concern, and it is one of the crucial factors of under-vaccination (4). WHO in 2019 stated that vaccine hesitancy is one of the top ten global health threats and it acts as a significant barrier to the success of the immunization programs (5). Interestingly, negative information about the vaccine propagated in some social media platforms might also have been contributing to vaccine hesitancy (6).

Earlier studies reported that vaccine hesitancy was a major concern worldwide with a wide range of reasons for vaccine refusal $(7,8)$. The most common reasons for vaccine hesitancy, in general, have been perceived risks vs. benefits of vaccine, religious considerations, and most importantly, lack of awareness and knowledge (9-11). To a great extent, these factors are also applicable for COVID-19 vaccine hesitancy in general public and HCWs. In this regard, recent studies demonstrated a significant correlation between willingness to receive COVID-19 and its safety outcome (12), negative attitude and unwillingness to receive COVID-19 vaccines (13), and, importantly, the effect of religious belief and decreased intention to receive COVID-19 vaccines (14). Further, willingness to accept vaccines is governed by various other factors such as cognitive, psychological, sociodemographic and cultural that can also influence individual response to vaccine hesitancy (15).

Healthcare workers (HCWs) orchestrate a vital role in the success of immunization programs. Studies indicated that their knowledge and attitude toward vaccines play an important role in the success of any immunization programs. It has been shown that their knowledge and attitudes about vaccines govern their own vaccine uptake intentions and recommendations to the wider general populations $(16,17)$. Emerging reports indicate that vaccine hesitancy in HCWs can negatively impact on vaccine acceptance in the general population $(18,19)$. HCWs who elicit negative attitudes are hesitant toward own vaccinations, and more importantly, they can amplify these undesirable perceptions resulting in even poorer uptake of vaccinations in their patients (20).

A recent wider population-based study of the adult Qatar general population displayed an overall vaccine hesitancy of $20 \%$ toward the COVID-19 vaccine (21). The present report

TABLE 1 | Demographic data and characteristics of participants $(n=1546)$.

\begin{tabular}{|c|c|c|}
\hline Variables & Frequency (n) & Percentage (\%) \\
\hline \multicolumn{3}{|l|}{ Age group } \\
\hline $18-25$ & 27 & 1.7 \\
\hline $26-35$ & 661 & 42.8 \\
\hline $36-45$ & 504 & 32.6 \\
\hline $46-55$ & 228 & 14.7 \\
\hline $56-65$ & 100 & 6.5 \\
\hline$>65$ & 26 & 1.7 \\
\hline \multicolumn{3}{|l|}{ Gender } \\
\hline Male & 672 & 43.5 \\
\hline Female & 874 & 56.5 \\
\hline \multicolumn{3}{|l|}{ Nationality } \\
\hline Qatari & 83 & 5.4 \\
\hline Arab-non-Qatari & 377 & 24.4 \\
\hline Asian & 807 & 52.2 \\
\hline African & 194 & 12.5 \\
\hline European & 61 & 3.9 \\
\hline North-America & 18 & 1.2 \\
\hline Central America & 4 & 0.3 \\
\hline South America & 2 & 0.1 \\
\hline \multicolumn{3}{|l|}{ Education } \\
\hline High school degree & 87 & 5.6 \\
\hline Trade/vocational training & 29 & 1.9 \\
\hline University & 1,226 & 79.3 \\
\hline Others & 204 & 13.2 \\
\hline \multicolumn{3}{|l|}{ Occupation } \\
\hline Salaried & 1,456 & 94.2 \\
\hline Self employed & 39 & 2.5 \\
\hline Unemployed & 24 & 1.6 \\
\hline Retired & 27 & 1.7 \\
\hline \multicolumn{3}{|l|}{ Marital status } \\
\hline Single & 285 & 18.4 \\
\hline Married & 1,261 & 81.6 \\
\hline $\begin{array}{l}\text { Are you pregnant or breast feeding? } \\
\text { Pregnant }\end{array}$ & 22 & 2.5 \\
\hline Breast feeding & 75 & 8.7 \\
\hline$N / A$ & 769 & 88.8 \\
\hline
\end{tabular}

How many members/individuals living with you?

Median (IQR)

$4.00(3.00)$ 
TABLE 2 | Intention to accept vaccine, health conditions, worries about COVID-19, and general attitude toward vaccination.

\begin{tabular}{|c|c|c|}
\hline Questions & Frequency (n) & Percentage (\%) \\
\hline \multicolumn{3}{|c|}{ Will you take the COVID-19 vaccine when it becomes available? } \\
\hline Definitely & 619 & 43.9 \\
\hline Probably & 255 & 18.0 \\
\hline Not sure & 358 & 25.3 \\
\hline Probably not & 92 & 6.5 \\
\hline Definitely not & 90 & 6.4 \\
\hline Total & 1,414 & 100.0 \\
\hline \multicolumn{3}{|c|}{ Have you completed your childhood vaccination? } \\
\hline Yes & 1,395 & 94.9 \\
\hline No & 75 & 5.1 \\
\hline Total & 1,470 & 100.0 \\
\hline \multicolumn{3}{|l|}{ How often you receive the influenza vaccine } \\
\hline Annually & 893 & 60.7 \\
\hline Twice & 176 & 12.0 \\
\hline Once & 190 & 12.9 \\
\hline Never & 211 & 14.4 \\
\hline Total & 1,470 & 100.0 \\
\hline \multicolumn{3}{|l|}{ Do you have any medical illness? } \\
\hline Yes & 324 & 22.0 \\
\hline No & 1,146 & 78.0 \\
\hline Total & 1,470 & 100.0 \\
\hline \multicolumn{3}{|l|}{ Chronic illnesses } \\
\hline DM & 120 & 32.97 \\
\hline HTN & 147 & 40.38 \\
\hline Dyslipidaemia & 43 & 11.81 \\
\hline Asthma & 44 & 12.09 \\
\hline IHD & 10 & 2.75 \\
\hline Total & 364 & 100.0 \\
\hline \multicolumn{3}{|l|}{ Do you have mental health illness? } \\
\hline Yes & 27 & 1.9 \\
\hline No & 1,431 & 98.1 \\
\hline Total & 1,458 & 1.9 \\
\hline \multicolumn{3}{|l|}{ Do you have any psychiatric disorders } \\
\hline Depression & 13 & 40.63 \\
\hline Anxiety & 17 & 53.12 \\
\hline Bipolar & 2 & 6.25 \\
\hline Total & 32 & 100 \\
\hline \multicolumn{3}{|l|}{ Do you have chronic medications? } \\
\hline Yes & 427 & 30.2 \\
\hline No & 987 & 69.8 \\
\hline Total & 1,414 & 100 \\
\hline \multicolumn{3}{|l|}{ Have you or family member had COVID-19? } \\
\hline I have had COVID-19 & 71 & 5.0 \\
\hline A family member has had COVID-19 & 84 & 5.9 \\
\hline $\begin{array}{l}\text { I and at least one family member has had } \\
\text { covid-19 }\end{array}$ & 61 & 4.3 \\
\hline Neither me nor them & 1,198 & 84.7 \\
\hline Total & 1,414 & 100.0 \\
\hline \multicolumn{3}{|c|}{ What are you most worried about during COVID-19? } \\
\hline Fear of becoming infected & 700 & $45.27 \%$ \\
\hline
\end{tabular}

(Continued)
TABLE 2 | Continued

\begin{tabular}{|c|c|c|}
\hline Questions & Frequency (n) & Percentage (\%) \\
\hline Fear of a family member to be infected & 962 & $62.2 \%$ \\
\hline Financial worries & 325 & 21.0 \\
\hline Job related worries & 444 & 28.7 \\
\hline No available vaccine & 539 & 34.9 \\
\hline Somewhat worried & 265 & 17.1 \\
\hline No worries & 159 & 10.3 \\
\hline Total & 1,546 & 100.0 \\
\hline \multicolumn{3}{|l|}{ Why you are willing to take the vaccine? } \\
\hline $\begin{array}{l}\text { My understanding of the disease and the } \\
\text { vaccination }\end{array}$ & 714 & 82.5 \\
\hline Information from my doctor/hospital & 81 & 9.4 \\
\hline Information from social media & 30 & 3.5 \\
\hline Information from news & 37 & 4.3 \\
\hline Information from family friend & 3 & 0.3 \\
\hline Total & 865 & 100.0 \\
\hline \multicolumn{3}{|l|}{ Will you recommend the vaccine? } \\
\hline Definitely & 613 & 44.0 \\
\hline probably & 289 & 20.8 \\
\hline not sure & 331 & 23.8 \\
\hline probably not & 82 & 5.9 \\
\hline Definitely not & 77 & 5.5 \\
\hline Total & 1,392 & 100.0 \\
\hline \multicolumn{3}{|l|}{ Will you get your children vaccinated? } \\
\hline Definitely & 550 & 39.5 \\
\hline probably & 278 & 20.0 \\
\hline not sure & 326 & 23.4 \\
\hline probably not & 131 & 9.4 \\
\hline definitely not & 107 & 7.7 \\
\hline Total & 1,392 & 100.0 \\
\hline \multicolumn{3}{|c|}{ Do you prefer to go Quarantine during traveling or take the vaccine? } \\
\hline I would definitely take the vaccine & 627 & 49.3 \\
\hline I would probably take the vaccine & 372 & 29.2 \\
\hline Not sure & 274 & 21.5 \\
\hline Total & 1,273 & 100.0 \\
\hline
\end{tabular}

specifically explores the hesitancy rates and attitudes among Qatar's HCWs toward COVID-19 vaccination.

\section{MATERIALS AND METHODS}

\section{Study Design}

We conducted a national cross-sectional survey in Qatar between October 15 and November 15, 2020, using an online survey among the HCWs. The survey link was posted online and advertised through local newspapers and various social media platforms of the Hamad Medical Corporation, the statefunded primary healthcare provider. The advertisements were accompanied by short videos in English and Arabic explaining the survey's rationale and nature. The survey was available in both English and Arabic languages. 


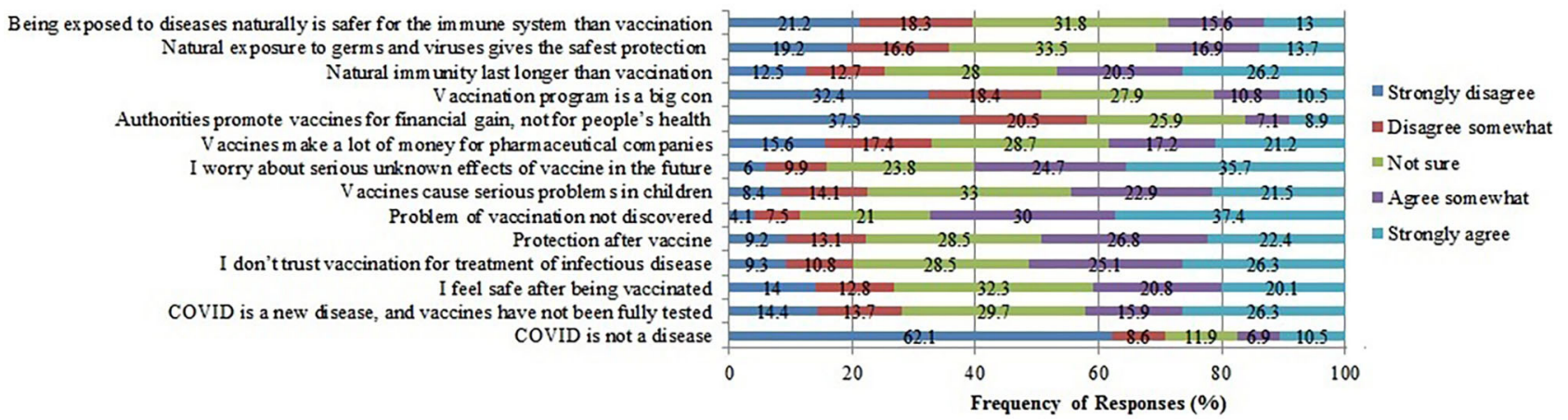

FIGURE 1 | Beliefs toward COVID-19 vaccine and immunity.

\section{Participants}

In the primary survey, all 2.3 million adult residents of Qatar were eligible. A total of 7,821 adults completed the survey. Among those, there were 1,546 HCWs, and the rest were general public. This report included 1,546 HCWs, 18 years of age and above, who consented to participate.

\section{Study Materials}

A validated vaccine hesitancy measurement tool, The Vaccine Attitudes Examination Scale (VAX) (22) was used as part of a composite questionnaire to assess the vaccine attitudes, awareness, and hesitancy among the study participants. This tool was translated into Arabic, and validation of the translated version was carried out using the guideline published by Sousa et al. (23). The survey also collected relevant demographic and contextual information of the participants.

\section{Outcome Measures}

The selection of study tools (VAX) and the composite questionnaire design were guided by the SAGE group recommendations to assess vaccine hesitancy. These included contextual factors such as ethnic origin, gender, socioeconomic status, educational level, media impact, and individual perception of the pharmaceutical industry; individual and group influences such as previous vaccination experience, beliefs and attitudes to vaccination in general, knowledge and awareness of the COVID-19 pandemic and vaccines, trust in health systems, and perception of risk and benefits of vaccines; and vaccine specific issues such as risks of a new vaccine, risk to children and older adults, and healthcare professionals' role.

\section{Data Analysis}

Descriptive statistics and multivariable logistic regression analysis were done using SPSS version 25.

\section{RESULTS}

\section{Demographics}

The total numbers of respondents of the study were 1,546. Forty two percent of the respondents were in the age group between $26-35$ years, followed by $32.6 \%$ in the age group between 36-45 years. Further, $56.5 \%$ of respondents were males, and $81.6 \%$ were married. The majority of the respondents were Asians (52.5\%), followed by Arab non-Qatari (24.4\%) and Qatari (5.4\%). Seventy nine percent were university graduates, and the majority of them were salaried employees (79.3\%). The data are shown in Table 1. We did not ask participants to identify their professions to improve the response rate and respecting their privacy.

\section{Intention to Accept the Vaccine, Health Conditions, Worries About COVID-19, and General Attitude Toward Vaccination}

In response to the question, "Will you take the COVID-19 vaccine when it becomes available?", $61.81 \%$ responded that they would "probably or definitely" accept the vaccine. Twenty five percent were unsure, and $12.9 \%$ responded that they would "probably or definitely" not take the vaccine.

Almost 95\% received childhood vaccination, 60.7\% received influenza vaccine annually, $78 \%$ revealed no history of any illness, $40.38 \%$ had hypertension, and $1.9 \%$ had mental health illness. The major worries were family members getting infected $(62.0 \%)$ or individuals getting infected $(45.3 \%)$. In response to the question, "why you are willing to take the vaccine?", $82.5 \%$ responded that they have a good understanding of the disease and the vaccination. Forty four percent of respondents reported that they would recommend the vaccine to others, $23.8 \%$ were unsure, and $20.8 \%$ reported probably they would take the vaccine. For the question, "Will you get your children vaccinated?", 39.5\% responded definitely, $23.4 \%$ were unsure, and $20 \%$ reported as probably. For the question, "Do you prefer to go quarantine during traveling or take the vaccine?, $49.3 \%$ responded that they would definitely take the vaccine during traveling, 29.2\% reported probably, and $21.5 \%$ were unsure. For the question, "Do you have any chronic medical conditions or are you taking any long-term medications", $61.6 \%$ reported that they had chronic condition. Only $11.7 \%$ had any chronic medical condition/s in the vaccine hesitancy group. The data are shown in Table 2. 
TABLE 3 | Univariate analysis of demographics, variables related to attitude and perception of vaccination, comparing vaccine hesitators and non-hesitators.

\begin{tabular}{|c|c|c|c|c|}
\hline \multirow[t]{3}{*}{ Variables } & \multicolumn{2}{|c|}{ Will you have the vaccine when it becomes available? } & \multirow{3}{*}{$\begin{array}{l}\text { Total } \\
n(\%)\end{array}$} & \multirow[t]{3}{*}{$p$-value } \\
\hline & YES & NO & & \\
\hline & $\begin{array}{l}\text { Vaccine non-hesitators } \\
\text { (definitely + probably) n (\%) }\end{array}$ & $\begin{array}{c}\text { Vaccine hesitators (definitely } \\
\text { not }+ \text { probably not) } \\
n(\%)\end{array}$ & & \\
\hline \multicolumn{5}{|l|}{ Age } \\
\hline from $36-45$ & $390(83.7)$ & $76(16.3)$ & $466(100.0)$ & \\
\hline from46-55 & $185(88.5)$ & $24(11.5)$ & 209 (100.0) & \\
\hline from 56-65 & 69 (81.2) & $16(18.8)$ & $85(100.0)$ & \\
\hline$>65$ & $2(10.0)$ & $18(90.0)$ & $20(100.0)$ & \\
\hline Total & $1,232(87.1)$ & $182(12.9)$ & $1,414(100.0)$ & \\
\hline \multicolumn{5}{|l|}{ Nationality } \\
\hline African & $159(91.4)$ & $15(8.6)$ & $174(100.0)$ & \\
\hline European & $46(79.3)$ & 12(20.7) & $58(100.0)$ & \\
\hline N. America & $11(64.7)$ & $6(35.3)$ & $17(100.0)$ & \\
\hline C. America & $4(100.0)$ & $0(0.0)$ & $4(100.0)$ & \\
\hline S. America & $2(100.0)$ & $0(0.0)$ & $2(100.0)$ & \\
\hline Total & $1,232(87.1)$ & $182(12.9)$ & $1,414(100.0)$ & \\
\hline Marital status & & & & 0.014 \\
\hline Single & $212(82.5)$ & $45(17.5)$ & $257(100.0)$ & \\
\hline Married & $1,020(88.2)$ & $137(11.8)$ & $1,157(100.0)$ & \\
\hline Total & $1,232(87.1)$ & $182(12.9)$ & $1,414(100.0)$ & \\
\hline Once & $147(81.2)$ & $34(18.8)$ & $181(100.0)$ & \\
\hline Never & $147(72.8)$ & $55(27.2)$ & $202(100.0)$ & \\
\hline Total & $1,232(87.1)$ & $182(12.9)$ & $1,414(100.0)$ & \\
\hline $\begin{array}{l}\text { Will you recommend the vaccine to } \\
\text { your children? }\end{array}$ & $546(99.3)$ & $4(0.7)$ & $550(100.0)$ & 0.001 \\
\hline Definitely & 277 (99.6) & $1(0.4)$ & $278(100.0)$ & \\
\hline Probably & $305(93.6)$ & $21(6.4)$ & $326(100.0)$ & \\
\hline Not sure & $64(48.9)$ & $67(51.1)$ & $131(100.0)$ & \\
\hline Probably not & $18(16.8)$ & 89 (83.2) & $107(100.0)$ & \\
\hline Definitely not & $1,210(86.9)$ & $182(13.1)$ & 1,392 (100.0) & \\
\hline Prefer quarantine over vaccine & & & & 0.001 \\
\hline Definitely will take the vaccine & $621(99.0)$ & $6(1.0)$ & $627(100.0)$ & \\
\hline Probably will take the vaccine & $354(95.2)$ & $18(4.8)$ & $372(100.0)$ & \\
\hline Not sure & $129(47.1)$ & $145(52.9)$ & $274(100.0)$ & \\
\hline Total & $1,104(86.7)$ & $169(13.3)$ & $1,273(100.0)$ & \\
\hline COVID-19 is not a disease & $718(90.9)$ & $72(9.1)$ & $790(100.0)$ & 0.001 \\
\hline Strongly disagree & $90(81.8)$ & $20(18.2)$ & $110(100.0)$ & \\
\hline Somewhat disagree & $121(80.1)$ & 30 (19.9) & $151(100.0)$ & \\
\hline
\end{tabular}


TABLE 3 | Continued

Variables
Will you YES
NO
Total

$n(\%)$ p-value

Vaccine hesitators (definitely not + probably not)

$n$ (\%)
Vaccine non-hesitators
(definitely + probably) n (\%)

$72(81.8)$

$103(76.9)$

$1,104(86.7)$

176 (96.2)

169 (96.6)

363 (96.0)

179 (88.6)

217(64.8)

$1,104(86.7)$

88 (49.4)

$126(77.3)$

$383(93.2 \%$

$258(97.4)$

$249(97.3)$

1,104 (86.7)

76 (64.4)

$103(74.6)$

317 (87.3)

295 (92.5)

313 (93.4)

1,104 (86.7)

61 (52.1)

$126(75.4)$

322(88.7)

325 (95.3)

$270(94.7)$

1,104 (86.7)

449 (93.9)

223 (85.4)

$288(87.3)$

$71(78.0)$

73 (64.6)

1,104(86.7)

375 (91.0)

198 (84.6)

309 (87.0)

$116(84.1)$

$106(79.1)$

1,104 (86.7)
16 (18.2)

31 (23.1)

169 (13.3)

7 (3.8)

$6(3.4)$

15 (4.0)

23 (11.4)

118 (35.2)

169 (13.3)

90 (50.6)

37 (22.7)

28 (6.8)

7 (2.6)

$7(2.7)$

169 (13.3)

42 (35.6)

35 (25.4)

46 (12.7)

$24(7.5)$

22 (6.6)

169 (13.3)

56 (47.9)

41 (24.6)

41 (11.3)

16 (4.7)

15 (5.3)

169 (13.3)

29 (6.1)

38 (14.6)

42 (12.7)

20 (22.0)

40 (35.4)

169 (13.3)

37 (9.0)

36 (15.4)

46 (13.0)

22(15.9)

28 (20.9)

169 (13.3)
88 (100.0)

134 (100.0)

1,273 (100.0)

183 (100.0)

0.001

175 (100.0)

378 (100.0)

202 (100.0)

335 (100.0)

1,273 (100.0)

178 (100.0)

0.001

$163(100.0)$

411 (100.0)

265 (100.0)

256 (100.0)

1,273 (100.0)

118 (100.0)

0.001

138 (100.0)

363 (100.0)

319 (100.0)

335 (100.0)

1,273 (100.0)

117 (100.0)

0.001

167 (100.0)

363 (100.0)

341 (100.0)

285 (100.0)

1,273 (100.0)

478 (100.0)

0.001

261(100.0)

330 (100.0)

91 (100.0\%

$113(100.0)$

$1,273(100.0)$

412(100.0)

$234(100.0)$

355 (100.0)

$138(100.0)$

$134(100.0)$

$1,273(100.0)$ 
TABLE 3 | Continued

Variables

\begin{tabular}{|c|c|}
\hline \multicolumn{2}{|c|}{ Will you have the vaccine when it becomes available? } \\
\hline YES & NO \\
\hline $\begin{array}{c}\text { Vaccine non-hesitators } \\
\text { (definitely + probably) } n \text { (\%) }\end{array}$ & $\begin{array}{c}\text { Vaccine hesitators (definitely } \\
\text { not }+ \text { probably not) } \\
n(\%)\end{array}$ \\
\hline
\end{tabular}

Natural immunity last longer than

vaccinations

$\begin{array}{lc}\text { Strongly disagree } & 147(92.5) \\ \text { Somewhat disagree } & 153(94.4) \\ \text { Not sure } & 316(88.5) \\ \text { Somewhat agree } & 227(87.0) \\ \text { Strongly agree } & 261(78.1) \\ \text { Total } & 1,104(86.7)\end{array}$

$12(7.5)$
$9(5.6)$
$41(11.5)$
$34(13.0)$
$73(21.9)$
$169(13.3)$

\section{VAX Scale of Hesitancy}

There were 14 questions in the VAX scale of hesitancy. The questions included "COVID is not a disease, COVID is a new disease and vaccines have not been fully tested, I feel safe after being vaccinated, I don't trust vaccination for treatment of infectious disease, I feel protected after vaccination, Problems of vaccination not yet discovered, Vaccines cause serious problems in children, I worry about serious unknown effects of vaccines in the future, Vaccines make a lot of money for pharmaceutical companies, Authorities promote vaccines for financial gain and not for peoples' health, Vaccination program is a big con, Natural immunity lasts longer than vaccination, Natural exposure to germs and viruses gives the safest protection, and Being exposed to diseases naturally is safer for the immune system than vaccination". The questions were rated as strongly agree, agree somewhat, not sure, disagree somewhat, and strongly disagree. The data are shown in Figure 1.

\section{Association Between Demographics, Variables Related to Attitude and Perception of Vaccination With Vaccine Hesitators vs. Non-hesitators}

We divided the responders into vaccine hesitators and vaccine non-hesitators, and their associations with sociodemographic variables and variables related to attitude and perception regarding vaccination were analyzed. Several sociodemographic factors were significantly associated with vaccine hesitancy, including age, nationality, marital status, and gender.

The other significant factors related to attitude and perception were influenza vaccination history, recommendation of vaccine to children, preference of quarantine over the vaccine, the perception that COVID-19 is not a disease, COVID-19 vaccine is not safe, no protection from the vaccine, lack of trust in the vaccine's efficacy, lack of trust of pharmaceutical companies and their intentions, and a belief that natural immunity is better than vaccination. The univariate analysis results are shown in Table 3.

Multivariate logistic regression for the response to the question "Will you take the COVID-19 vaccine when it becomes available" (vaccine hesitancy) as the dependent (outcome) variable and items of VAX scale, sociodemographic variables and a few other items related to influenza vaccine as the independent (predictor) variables was done, after controlling for age, education, nationality, marital, and employment status. Female gender, "I feel safe after being vaccinated (strongly disagree, somewhat disagree, not sure)", "Covid-19 is a new disease and vaccines against it have not been fully tested and will not be safe (strongly disagree, somewhat disagree, not sure)", "I feel protected after being vaccinated (not sure)", and "I worry about the unknown effects of vaccines in the future (somewhat disagree, not sure)", were significantly associated with vaccine hesitancy. The results were shown in Table 4.

\section{DISCUSSION}

Our study is one of the largest surveys that addressed the attitudes toward vaccination in HCWs in the Middle East during the COVID-19 pandemic. The main finding of this study is that among the surveyed HCWs, $12.9 \%$ displayed hesitancy toward getting vaccinated with a COVID-19 vaccine, and a further $25.31 \%$ were unsure whether they would accept the vaccination or not. In a recent survey conducted among the Saudi HCWs ( $n=736)$ in December 2020, using a non-standardized survey questionnaire, the vaccine hesitancy rate was reported to be $49.48 \%$ (24). Similarly, in an online survey conducted among the French HCWs between March and July 2020, the vaccine hesitancy rate reported was $25.9 \%$ (25). Another study done by Di Gennaro et al. (26) among the Italian HCWs, reported a vaccine hesitancy of $7 \%$. The vaccine hesitancy rate of $12.9 \%$ in our study is much lower than the Saudi and French studies and slightly higher than the Italian study. This variation might be a reflection of the study methodology, the representative population, and the different healthcare systems.

In our study, age (older than 65 years) was significantly associated with vaccine hesitancy, which is in corroboration with the survey done by Schwarzinger et al. (27) where age displayed an inverted U-shaped relationship. In the same study, vaccine hesitancy was significantly higher in females than males, which is 
TABLE 4 | Multivariate logistic regression showing predictors of vaccine hesitancy.

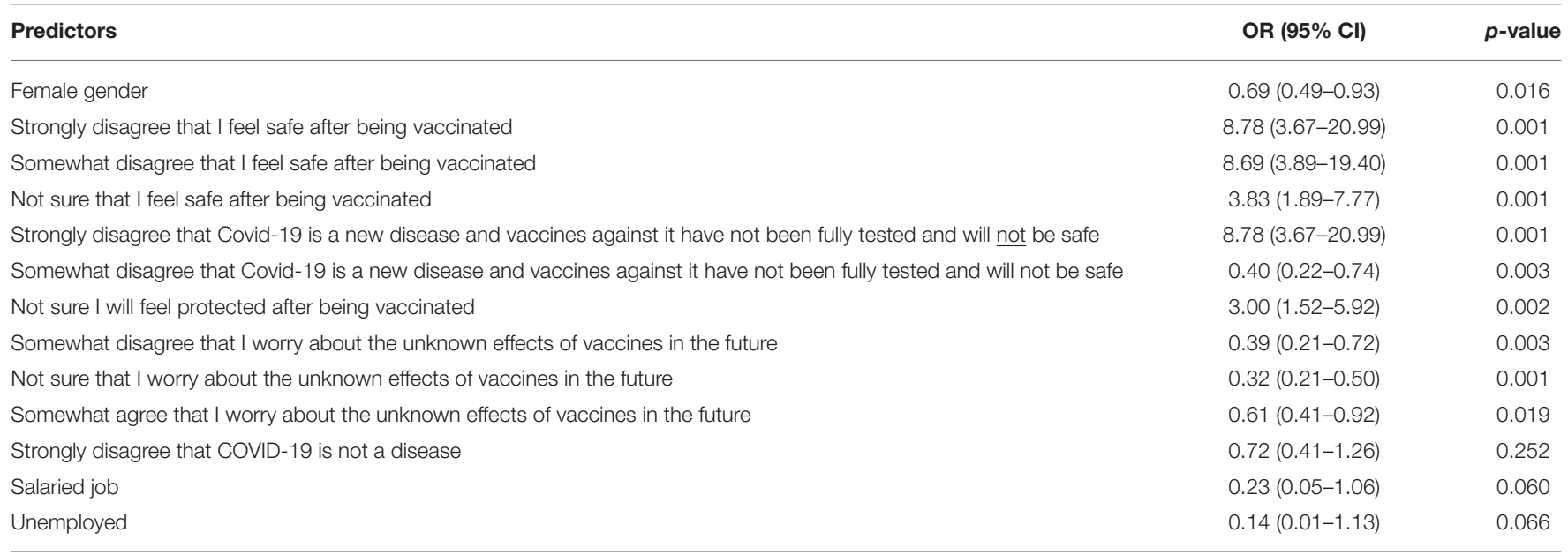

in line with our finding. A possible reason may be that females often consider the impact on their children and fertility (25). However, in contrast, in a study conducted in Saudi Arabia, the vaccine hesitancy was higher in males than females, although we don't have an explanation for this discrepancy (24). In our study, marital status has a strong influence on vaccine hesitancy, particularly among the married respondents. Previous studies also showed that marital status might affect vaccine hesitancy, with single parents or those divorced demonstrating increased vaccine hesitancy (28).

The main reason for vaccine acceptance in our survey was a better understanding of the disease and vaccines, which possibly enables the respondents to make an informed and confident decision on vaccine acceptance. Interestingly, a previous study showed that perceived susceptibility to and seriousness of a vaccine-preventable disease as an indicator of a better understanding of the disease that might lead to vaccine acceptance (25).

Recent studies showed that HCWs willing to accept the vaccine were more likely to recommend vaccines to friends, family, and patients (27-29). Similar findings were observed in our study.

In the VAX hesitancy scale, $26.3 \%$ of respondents reported negative attitudes about safety and trust about the vaccines. Furthermore, the hesitancy was also attributed to the concerns regarding safety among the children in their family, the chance of getting any unknown illness in the future, and a preference for natural over vaccine-induced immunity. Similar findings were also observed in our main survey on the general population (21) suggesting that these findings are not specifically applied to only HCWs.

Of note, on multivariate analysis, we found female gender, the perception that vaccines are not safe at the time of vaccination, a perceived lack of safety after vaccination, and doubts over vaccine protection were the significant predictors of vaccine hesitancy. Interestingly, having a chronic medical condition was not a significant predictor. To date, there are no large cohort studies available to authenticate the efficacy of COVID-19 vaccines.
Therefore, the first generation may have limited efficacy, which leads to a loss of trust in the current COVID-19 vaccines (30). A previous study indicated that the safety, efficacy, and effectiveness of COVID-19 were the hallmark predictors of COVID-19 vaccine hesitancy (31).

The present study was conducted in a distinct part of the globe with diverse demographics, and the majority were migrant populations, including the HCWs. We also surveyed when COVID-19 vaccine producers reported their efficacy data and initiated mass immunization programs worldwide. Besides, we used a validated vaccine hesitancy tool, and the outcome measures were based on internationally established vaccine hesitancy parameters.

\section{CONCLUSION}

Vaccine hesitancy has a significantly negative impact on a planned immunization program's successful outcome, and it has been considered a global threat to universal immunization programs. In our study, the majority of the HCWs accepted to take the COVID-19 vaccine. However, 1 in $8 \mathrm{HCW}$ s was vaccine hesitant. The significant predictors of vaccine hesitancy were female gender, concerns about vaccine safety, safety after the vaccination, and doubts about the vaccine's protection. Education about the vaccine's safety and efficacy can potentially improve acceptance among healthcare workers.

\section{DATA AVAILABILITY STATEMENT}

The raw data supporting the conclusions of this article will be made available by the authors, without undue reservation.

\section{ETHICS STATEMENT}

The studies involving human participants were reviewed and approved by Medical Research Council of the Hamad Medical Corporation. MRC approval-01-20-930. The 
patients/participants provided their written informed consent to participate in this study.

\section{AUTHOR CONTRIBUTIONS}

RK: conceptualization, data analysis, and interpretation and writing-original draft and editing. MA: conceptualization, methodology, supervision, validation, and writing-review and editing. NE: data analysis, interpretation, and writing-editing. SR: conceptualization, methodology, supervision, validation, and writing-review and editing. All authors contributed to the

\section{REFERENCES}

1. Sherman SM, Smith LE, Sim J, Amlot R, Cutts M, Dasch H, et al. COVID-19 vaccination intention in the UK: results from the COVID19 vaccination acceptability study (CoVAccS), a nationally representative cross-sectional survey. Hum Vaccin Immunother. (2020) 17:1612-21. doi: 10.1080/21645515.2020.1846397

2. Lurie N, Saville M, Hatchett R, Halton J. Developing Covid-19 vaccines at pandemic speed. $N$ Engl J Med. (2020) 382:1969-73. doi: 10.1056/NEJMp2005630

3. Dodd RH, Cvejic E, Bonner C, Pickles K, McCaffery KJ. Willingness to vaccinate against COVID-19 in Australia. Lancet Infect Dis. (2021) 21:318-19. doi: 10.1016/S1473-3099(20)30559-4

4. MacDonald NE. SAGE working group on vaccine hesitancy. Vaccine hesitancy: definition, scope and determinants. Vaccine. (2015) 33:4161-4. doi: 10.1016/j.vaccine.2015.04.036

5. World Health Organisation (WHO). Ten threats to global health in 2019. ANMJ (2019).

6. Dhaliwal D, Mannion C. Antivaccine messages on facebook: preliminary audit. JMIR Public Heal Surveill. (2020) 6:e18878. doi: 10.2196/18878

7. The Lancet Child Adolescent Health. Vaccine hesitancy: a generation at risk. Lancet Child Adolesc Heal. (2019) 3:281. doi: 10.1016/S2352-4642(19) 30092-6

8. Wagner AL, Masters NB, Domek GJ, Mathew JL, Sun X, Asturias EJ, et al. Comparisons of vaccine hesitancy across five low- and middle-income countries. Vaccines. (2019) 7:155. doi: 10.3390/vaccines7040155

9. Karafillakis E, Larson HJ. The benefit of the doubt or doubts over benefits? A systematic literature review of perceived risks of vaccines in European populations. Vaccine. (2017) 35:4840-50. doi: 10.1016/j.vaccine.2017.07.061

10. Pelčić G, Karačić S, Mikirtichan GL, Kubar OI, Leavitt FJ, Tai MC, et al. Religious exception for vaccination or religious excuses for avoiding vaccination. Croat Med J. (2016) 57:516-21. doi: 10.3325/cmj.2016.57.516

11. Yaqub $\mathrm{O}$, Castle-Clarke S, Sevdalis N, Chataway J. Attitudes to vaccination: a critical review. Soc Sci Med. (2014) 112:1-11. doi: 10.1016/j.socscimed.2014.04.018

12. Karlsson LC, Soveri A, Lewandowsky S, Karlsson L, Karlsson H, Nolvi S, et al. Fearing the disease or the vaccine: the case of COVID-19. Pers Individ Dif. (2021) 172:110590. doi: 10.1016/j.paid.2020.110590

13. Paul E, Steptoe A, Fancourt D. Attitudes towards vaccines and intention to vaccinate against COVID-19: implications for public health communications. Lancet Reg Heal - Eur. (2021) 1:100012. doi: 10.1016/j.lanepe.2020.100012

14. Olagoke AA, Olagoke OO, Hughes AM. Intention to vaccinate against the novel 2019 coronavirus disease: the role of health locus of control and religiosity. J Relig Health. (2021) 60:65-80. doi: 10.1007/s10943-020-01090-9

15. Pomares TD, Buttenheim AM, Amin AB, Joyce CM, Porter RM, Bednarcyk RA, et al. Association of cognitive biases with human papillomavirus vaccine hesitancy: a cross-sectional study. Hum Vaccin Immunother. (2020) 16:101823. doi: 10.1080/21645515.2019.1698243

16. Nzaji KM, Ngombe LK, Mwamba GN, Ndala DBB, Miema JM, Lungoyo CL, et al. Acceptability of vaccination against covid-19 among healthcare workers in the democratic republic of the congo. Pragmatic Obs Res. (2020) 11:103-9. doi: 10.2147/POR.S271096 interpretation of the results, critically revised the paper, and agreed on the final version for submission.

\section{ACKNOWLEDGMENTS}

We would like to thank the Medical Research Center (MRC) of the Hamad Medical Corporation for their support. We also would like to thank Prof. Leslie Martin for her kind permission to use the Vaccination Attitudes Examination (VAX) Scale.

Open Access funding provided by the Qatar National Library.

17. Hollmeyer HG, Hayden F, Poland G. Buchholz Udo. Influenza vaccination of health care workers in hospitals-a review of studies on attitudes and predictors. Vaccine. (2009) 27:3935-44. doi: 10.1016/j.vaccine.2009.03.056

18. Verger P, Fressard L, Collange F, Gautier A, Jestin C, Launay O, et al. Vaccine hesitancy among general practitioners and its determinants during controversies: a national cross-sectional survey in France. EBioMedicine. (2015) 2:891-97. doi: 10.1016/j.ebiom.2015.06.018

19. Schwarzinger M, Verger P, Guerville M-A, Aubry C, Rolland S, Obadia $\mathrm{Y}$, et al. Positive attitudes of French general practitioners towards A/H1N1 influenza-pandemic vaccination: a missed opportunity to increase vaccination uptakes in the general public? Vaccine. (2010) 28:2743-8. doi: 10.1016/j.vaccine.2010.01.027

20. Arda B, Durusoy R, Yamazhan T, Sipahi OR, Tasbakan M, Pullukcu H, et al. Did the pandemic have an impact on influenza vaccination attitude? A survey among health care workers. BMC Infect Dis. (2011) 11:87. doi: 10.1186/1471-2334-11-87

21. Alabdulla M, Reagu SM, Al-Khal A, Elzain M, Jones RA. COVID-19 vaccine hesitancy and attitudes in Qatar: a national cross-sectional survey of a migrant-majority population. Influenza Other Respi Viruses. (2021) 15:36170. doi: 10.1111/irv.12847

22. Martin LR, Petrie KJ. Understanding the dimensions of anti-vaccination attitudes: the vaccination attitudes examination (VAX) scale. Ann Behav Med. (2017) 51:652-60. doi: 10.1007/s12160-017-9888-y

23. Sousa VD, Rojjanasrirat W. Translation, adaptation and validation of instruments or scales for use in cross-cultural health care research: a clear and user-friendly guideline. J Eval Clin Pract. (2011) 17:268-74. doi: 10.1111/j.1365-2753.2010.01434.x

24. Qattan AMN, Alshareef N, Alsharqi O, Rahahleh NA, Chirwa GC, AlHanawi MH. Acceptability of a COVID-19 vaccine among healthcare workers in the kingdom of Saudi Arabia. Front Med. (2021) 8:e644300. doi: 10.3389/fmed.2021.644300

25. Gagneux-Brunon A, Detoc M, Bruel S, Tardy B, Rozaire O, Frappe P, et al. Intention to get vaccinations against COVID-19 in French healthcare workers during the first pandemic wave: a cross-sectional survey. J Hosp Infect. (2021) 108:168-73. doi: 10.1016/j.jhin.2020.11.020

26. Di Gennaro F, Murri R, Segala FV, Cerruti L, Abdulle A, Saracino A, et al. Attitudes towards Anti-SARS-CoV2 vaccination among healthcare workers: results from a national survey in Italy. Viruses. (2021) 13:371. doi: $10.3390 /$ v13030371

27. Schwarzinger M, Watson V, Arwidson P, Alla F, Luchini A. COVID19 vaccine hesitancy in a representative working-age population in France: a survey experiment based on vaccine characteristics. Lancet Public Healh. (2021) 6:E210-21. doi: 10.1016/S2468-2667(21) 00012-8

28. Shacham M, Greenblatt-Kimron L, Hamama-Raz Y, Martin LR, Peleg O, Ben-Ezra M, et al. Increased COVID-19 vaccination hesitancy and health awareness amid COVID-19 vaccinations programs in Israel. Int J Environ Res Public Health. (2021) 18:3804. doi: 10.3390/ijerph180 73804

29. Paterson P, Meurice F, Stanberry LR, Gilsmann S, Rosenthal SL, Larson HJ. Vaccine hesitancy and healthcare providers. Vaccine. (2016) 34:6700-6. doi: 10.1016/j.vaccine.2016.10.042 
30. Torreele E. The rush to create a covid-19 vaccine may do more harm than good. BMJ. (2020) 370:m3209. doi: 10.1136/bmj. m3209

31. Wang K, Wong ELY, Ho KF, Cheung AWL, Chan EYY, Yeoh EK, et al. Intention of nurses to accept coronavirus disease 2019 vaccination and change of intention to accept seasonal influenza vaccination during the coronavirus disease 2019 pandemic: a cross-sectional survey. Vaccine. (2020) 38:7049-56. doi: 10.1016/j.vaccine.2020. 09.021

Conflict of Interest: The authors declare that the research was conducted in the absence of any commercial or financial relationships that could be construed as a potential conflict of interest.
Publisher's Note: All claims expressed in this article are solely those of the authors and do not necessarily represent those of their affiliated organizations, or those of the publisher, the editors and the reviewers. Any product that may be evaluated in this article, or claim that may be made by its manufacturer, is not guaranteed or endorsed by the publisher.

Copyright (C) 2021 Kumar, Alabdulla, Elhassan and Reagu. This is an open-access article distributed under the terms of the Creative Commons Attribution License (CC $B Y)$. The use, distribution or reproduction in other forums is permitted, provided the original author(s) and the copyright owner(s) are credited and that the original publication in this journal is cited, in accordance with accepted academic practice. No use, distribution or reproduction is permitted which does not comply with these terms. 